\title{
Thermal front variability along the North Atlantic Current observed using microwave and infrared satellite data Peter I. Miller ${ }^{1}$, Jane F. Read ${ }^{2}$ and Andrew C. Dale ${ }^{3}$ \\ ${ }^{1}$ Remote Sensing Group, Plymouth Marine Laboratory, Prospect Place, Plymouth PL1 3DH, UK. E-mail pim@pml.ac.uk. \\ ${ }^{2}$ National Oceanography Centre, European Way, Southampton SO14 3ZH, UK. \\ ${ }^{3}$ Scottish Association for Marine Science, Oban, Argyll PA37 1QA, UK
}

\begin{abstract}
Thermal fronts detected using multiple satellite sensors have been integrated to provide new information on the spatial and seasonal distribution of oceanic fronts in the North Atlantic. The branching of the North Atlantic Current (NAC) as it encounters the Mid-Atlantic Ridge (MAR) is reflected in surface thermal fronts, which preferentially occur at the Charlie Gibbs Fracture Zone (CGFZ) and several smaller fracture zones. North of the CGFZ there are few thermal fronts, contrasting with the region to the south, where there are frequent surface thermal fronts that are persistent seasonally and interannually. The alignment of the fronts confirms that the shallower Reykjanes Ridge north of the CGFZ is more of a barrier to water movements than the ridge to the south. Comparison of front distributions with satellite altimetry data indicates that the MAR influence on deep ocean currents is also frequently exhibited in surface temperature. The improved spatial and temporal resolution of the front analysis has revealed consistent seasonality in the branching patterns. These results contribute to our understanding of the variability of the NAC, and the techniques for visualising oceanic fronts can be applied in other regions to reveal details of surface currents that cannot be resolved using satellite altimetry or in situ measurements.
\end{abstract}

Keywords: Oceanic fronts; Passive microwave; Infrared imagery; Altimetry; Mid-Atlantic Ridge; Charlie -Gibbs Fracture Zone; North Atlantic Current; Ocean circulation.

Article info: Miller, P.I., Read, J.F. \& Dale, A.C. (2013) Thermal front variability along the North Atlantic Current observed using microwave and infrared satellite data. Deep Sea Research Part II, 98, Part B, 244-256. doi: 10.1016/j.dsr2.2013.08.014. This document is the author's post-print.

\section{Introduction}

Upper ocean flow in the northern North Atlantic is dominated by the several-branched, northeastflowing North Atlantic Current (NAC). This flow, an extension of the Gulf Stream, is the northern arm of the subtropical gyre and transports warm water towards higher latitudes as part of the global thermohaline circulation. The Mid-Atlantic Ridge (MAR) is a major topographic barrier to the NAC (Figure 1), the branches of which tend to be guided across the MAR by a number of deep fracture zones between $45^{\circ} \mathrm{N}$ and $53^{\circ} \mathrm{N}$. The northern branch of the NAC passes through the Charlie-Gibbs Fracture Zone (CGFZ) at $52^{\circ} \mathrm{N}$ (Rossby, 1996, Bower et al., 2002), providing a distinct northern edge to the subpolar front (SPF), the boundary between the subpolar and subtropical waters. The remaining branches are more variable and loosely tied to the Faraday, Maxwell and Bight Fracture Zones (Bower et al., 2002, Bower and von Appen, 2008). Understanding the seasonal and interannual variability of the NAC pathways is important for ocean and climate predictions.

The aim of the ECOMAR project (Ecosystems of the Mid-Atlantic Ridge at the subpolar front and CGFZ) was to understand how physical and biogeochemical factors influence the distribution and structure of deep-sea communities, focusing on the fauna of the MAR. In particular the project sought to determine whether productivity and biodiversity associated with the ridge were enhanced compared with adjacent open ocean areas (Priede et al., 2013b). Abundant and diverse marine life requires enhanced nutrient availability and it was hypothesised that the presence of the MAR would increase 
mixing, elevate nutrient concentrations and provide the ideal conditions for increased marine productivity and biodiversity (Priede et al., 2013a).

The objective of this paper is to use Earth observation (EO) data to investigate thermal fronts across the MAR, their variability and longevity, and to relate these to the deeper oceanic structure through comparison with sea surface height measurements. A thermal front can indicate several aspects of surface structure. It may delineate a strong jet, representing a density gradient of significant vertical extent; it may show local enhancement of a weak gradient by mesoscale shear and strain; it may be due to enhanced mixing breaking through the seasonal stratification; or it may represent a shallow structure with little dynamical significance.

New front detection methods (Miller, 2009), based on merged microwave and infrared data, are used to identify surface thermal fronts. Infrared measurements of sea surface temperature are limited by cloud cover that prevents remote observations being made. This is a particular problem over frontal regions such as the subpolar front, which have therefore only rarely been studied using satellite infrared data (Flatau et al., 2003). Such data have been used to map the long-term mean position of fronts in large marine ecosystems (Belkin et al., 2009). Passive microwave sensors can now estimate sea surface temperature through cloud cover, although at a lower resolution. The new, combined dataset exceeds the spatial and temporal resolution possible with previous gridded products, providing improved resolution of surface thermal fronts. Here we investigate whether this combined dataset can extend our knowledge of the seasonal and interannual variability of the NAC pathways and their relationship to the bathymetry of the MAR. Comparisons are drawn with studies of the surface topography and upper-ocean currents obtained from satellite altimetry and drifters (Bower and von Appen, 2008).

\section{Methods}

\section{Sea-surface temperature data}

The initial source of data for this frontal analysis was the Advanced Very High Resolution Radiometer (AVHRR) archive acquired by Dundee Satellite Receiving Station, comprising several passes per day over the North Atlantic continuously since August 1981 (Miller et al., 1997). The maximum spatial resolution is $1.1 \mathrm{~km}$, sufficient for detection of all scales of fronts relevant to the MAR. 28 years of data were processed to encompass the interannual variability, from August 1981 to December 2008.

The first stage was to convert the raw infrared AVHRR data into sea surface temperature (SST) maps. The Panorama system (Miller et al., 1997) enabled the data to be calibrated into SST values, navigated, cloud-masked and mapped consistently for the MAR region. For the sequence, over 24,000 AVHRR passes were processed. The SST data were mapped into Mercator projection, with a spatial resolution of approximately $1.1 \mathrm{~km} /$ pixel.

The second stage was to detect ocean fronts on every individual SST scene and combine them to generate monthly front maps. Algorithms enable fronts to be located accurately and objectively. The criteria for detecting a front are that there are distinct cold and warm modes of the temperature histogram within a local window (32x32 pixels); a minimum step of $0.4^{\circ} \mathrm{C}$ across the front; and the cold and warm pixels form contiguous areas. The selected window size provides sufficient pixel samples to allow sensitive detection of a bimodal distribution, while limiting the inclusion of more than two water masses in the window; and this has been found to be applicable to different resolutions. The minimum step of $0.4^{\circ} \mathrm{C}$ identifies most genuine fronts without confusing the map with too many weaker structures. The composite front map technique combines the location, gradient, persistence and proximity of all fronts observed over a given period into a single map (Miller, 2009). Despite the severe cloud cover in the NE Atlantic, this approach combines the available evidence for fronts without blurring dynamic features, an inherent problem with conventional time-averaging methods. It is important to emphasise that fronts are not detected on monthly SST composites, but 
rather on individual SST 'snapshots' that reveal the detailed thermal structure without averaging artefacts.

Eight-day composite front maps were also derived from daily merged microwave and infrared SST data from 2006 to 2011 provided by Remote Sensing Systems, USA. These SST maps improve upon the $25 \mathrm{~km}$ resolution of the microwave sensors (AMSR-E, TMI and WindSAT) by merging with all cloud-free $1 \mathrm{~km}$ infrared SST data using optimal interpolation onto a $9 \mathrm{~km}$ grid (Gentemann et al., 2009). In addition, in order to visualise the variability of the time series, 7-day front maps were generated from the merged SST data on a rolling basis (each offset by 1 day), and spatially smoothed using a $5 \times 5$ pixel Gaussian filter to provide a metric of localised front density.

\section{Frequent front maps}

The next stage of analysis was to aggregate the monthly or 8-day front maps into seasonal front climatologies to identify strong, persistent and frequently occurring features. An algorithm was developed to perform this aggregation, and estimates the percentage of time a strong front is observed within each grid location. This algorithm has been previously applied to describe the front distribution in the UK shelf seas (Miller and Christodoulou, in press).

Each grid cell and month in the time-series was analysed according to the total number of satellite passes, the number of cloud-free observations (valid if at least 1), and whether a strong front was indicated. The normal indication of a strong front is that the combined strength and persistence value $\left(\mathrm{F}_{\text {comp }}\right)$ is greater than a certain threshold; however the cloud cover in this region was so great that the results were found to be more reliable using a low threshold on the mean gradient of detected fronts: $F_{\text {mean }} \geq 0.04{ }^{\circ} \mathrm{C} \mathrm{km}^{-1}$. These quantities were then used to generate seasonal maps of frequent fronts, interannual standard deviation and data quantity. For AVHRR data these metrics were generated at a reduced resolution of $4.4 \mathrm{~km} / \mathrm{pixel}$; although this reduced fine scale structure, it made features more prominent as small offsets of the same feature over the time-series were accumulated. For merged SST data, the threshold was selected: $\mathrm{F}_{\text {mean }} \geq 0.1^{\circ} \mathrm{C} \mathrm{km}^{-1}$; and the $9 \mathrm{~km}$ resolution was not changed for the metrics. Also the aggregation was performed on 8-day rather than monthly composites, due to the increased cloud-penetrating observations of fronts.

The following calendar seasons were used: winter: December to February; spring: March to May; summer: June to August; and autumn: September to November.

\section{Altimetry data}

Altimetry data were obtained from the SSALTO/DUACS (Segment Sol multimissions d'altimétrie, d'orbitographie et de localisation precise/Developing use of altimetry for climate studies) multimission altimeter data processing system distributed by CLS/AVISO (Collecte Localis Satellites/Archivage, Validation, Interprétation des données des Satellite Océanographiques). Sea surface height and surface geostrophic velocity were extracted from maps of absolute dynamic topography (MADT) generated from combined merged altimetry data from all available satellite altimeters. The resolution is $1 / 3^{\circ}$ on a Mercator grid. Data between October 1992 and 10 June 2009 were processed on 3 May 2010. Data after this were processed on 29 March 2011. To compare results with those of Bower and von Apen (2008), sea surface height and surface geostrophic velocity were extracted along $35^{\circ} \mathrm{W}$ and $29^{\circ} \mathrm{W}$ between $45^{\circ}$ to $55^{\circ} \mathrm{N}$. The main difference between Bower and von Apen's data set and that used here is the use of the new Mean Dynamic Topography, MDT-CNESCLS09, to replace the earlier Rio05 model (Rio et al., 2011) in calculating the absolute dynamic topography.

To focus attention on the interannual time scale, Bower and von Apen (2008) used a third-order Butterworth filter with a cut-off period of 90 days. Data used in this paper were filtered over 88 days with a top-hat filter. The two data sets appeared directly comparable so no further processing was done. For this paper the time period was extended until December 2010 to increase the overlap with the merged microwave data. 


\section{Results and discussion}

\section{Circulation from altimetry}

The circulation shown by the mean absolute dynamic topography (Figure 2) is similar to that obtained by other analyses such as streamfunctions derived from floats and drifters (Krauss, 1986, Bower et al., 2002, Perez-Brunius et al., 2004, Jayne, 2006) and illustrates the major circulation features of the central North Atlantic. Closely-spaced contours of sea surface topography in the west follow the eastward NAC across the MAR. The flow then spreads out and weakens, with one component circulating cyclonically within the subpolar gyre (Pollard et al., 1996, van Aken and Becker, 1996), a second component passing between Iceland and Scotland, and a third component veering southward in the subtropical gyre, where the strongest component forms the Azores Current. The subpolar gyre component crosses the Reykjanes Ridge in a westward direction and flows to the north along its western flank as the Irminger Current. Closely-spaced contours in the northwest indicate the East Greenland Current.

The circulation of the subpolar gyre is strongly influenced by the topography. Thus, much of the flow follows the boundary of the North Atlantic (Figure 2). However, the major topographic feature of the North Atlantic is the Mid-Atlantic Ridge (Figure 1) and it is noticeable that there is no deflection in the mean flow where it crosses the MAR in an eastward direction (between $48-54^{\circ} \mathrm{N}, 28-36^{\circ} \mathrm{W}$ ). This figure does not depict persistent eddies and meanders previously observed in the vicinity of the ridge (Bower and von Appen, 2008, Read et al., 2010), although these are evident elsewhere, such as to the west of Ireland and into the Iceland Basin $\left(53-58^{\circ} \mathrm{N}, 15-25^{\circ} \mathrm{W}\right)$ (Shoosmith et al., 2005).

ECOMAR studied four main mooring stations arranged in two pairs, north and south of the CGFZ, with each pair spanning the MAR. The two northern stations were in the interior of the subpolar gyre and the two southern stations were situated within the broad band of eastward flow of the NAC.

We will now analyse thermal fronts for evidence of topographic influence of the MAR.

\section{Seasonal variability of thermal fronts}

\section{Infrared data}

Figure 3 shows seasonal front frequency maps based on the $1.1 \mathrm{~km}$ resolution AVHRR infrared data from 1981 to 2008. The most significant feature in all seasons is the contrast between the zones north and south of $52^{\circ} \mathrm{N}$ : there is a wide band of higher front frequency to the south and very few fronts to the north. The CGFZ bisects the MAR at approximately $52^{\circ} \mathrm{N}$ and it is known that this fracture guides the path of the northern branch of the NAC through the MAR (Belkin and Levitus, 1996, Bower et al., 2002). This figure shows that the topographic steering of the NAC also dominates the occurrence of surface thermal fronts at the MAR.

The majority of the surface fronts lie in a broad band south of the CGFZ that increases in density and southerly extent during spring and summer. The virtual absence of features north of the CGFZ suggests a less dynamic region, where the generation of thermal fronts by mesoscale stretching and straining or surface forcing is less prevalent. The boundary between the two regions is clearly topographically related. The disparity between north and south will have an important impact on upper ocean biological activity, as surface thermal fronts and associated mesoscale activity will drive secondary circulation which will maintain nutrient supply to the euphotic layer. Tilstone et al. (in press) found that the SPF is 4 times more productive relative to its area than regions to the north and south of the SPF.

The zone south of CGFZ $\left(52^{\circ} \mathrm{N}\right)$ is uniformly high in fronts with no coherent peaks of front frequency that could be associated with the underlying topography. Rather, it suggests a zone of stochastic eddying. The exception to this is a band of frequent fronts northeast of $52^{\circ} \mathrm{N}, 28^{\circ} \mathrm{W}$ where a meanderlike feature is revealed. There is also a small increase in front frequency along the northern edge of the zone, between $51^{\circ}-52.5^{\circ} \mathrm{N}$, which is present in winter and more pronounced in spring. 


\section{Merged microwave and infrared data}

Although the frontal analysis of infrared data has revealed new information on surface structure, it is also apparent that persistent cloud cover restricted the potential analysis of even a 28 -year data set. Most of the region had cloud-free observations less than $8 \%$ of the time. Therefore the analysis was repeated and extended by merging microwave observations with the infrared data set. The microwave data enable major thermal features to be detected even when they are cloud-covered.

Figure 4 shows the surface oceanic thermal front frequency distribution for spring using the combined data set. The most striking aspect is the clearer picture that emerges, with defined bands of higher and lower frequency of surface thermal fronts. The primary feature across the MAR is still the high frequency of fronts associated with the CGFZ while the region immediately north of the CGFZ still shows few frontal features. On the basin scale, the frequent fronts now outline major features of the circulation of the subpolar gyre. The broadening of the NAC after crossing the MAR is marked by less frequent occurrence of fronts, but branches into the Iceland Basin and Rockall Trough are clear. Surface fronts are frequently observed directly above the Rockall Bank (labelled B) and off the Irish continental shelf. The northern boundary of the subpolar gyre, east and west of Iceland is marked by very frequent thermal fronts, as is the East Greenland Current, and the West Greenland Current.

Returning to the region of interest, over the MAR, the thermal fronts associated with the CGFZ at $52^{\circ} \mathrm{N}$ are now distinguishable from features to the south. For example, at ' $\mathrm{M}$ ' thermal fronts occur frequently either side of the ridge crest and appear to delineate a northward meander of the current branch (also indicated in Figure 7 below). At $46-47^{\circ} \mathrm{N}$ there is another near continuous band of fronts between $34^{\circ} \mathrm{W}$ and $26^{\circ} \mathrm{W}$. Arrows overlaid on the frequent front map (Figure 4) indicate possible paths of continuous currents inferred from the front and altimetry data, and corroborates earlier observations that the flow branches as it approaches and crosses the MAR (e.g. Bower and von Appen, 2008).

The northernmost waters of the NAC circulate weakly cyclonically to the east of the MAR until encountering the Reykjanes Ridge ( $R$ in Figure 4). They then flow to the $S W$ along its eastern flank before crossing to the western flank and intensifying as the NE-flowing Irminger Current. The boundary between this water and the cooler waters of the Irminger Sea is broad and diffuse, associated with increased occurrence of SST fronts both along the Irminger Current and in the central Irminger Basin ( $\mathrm{N}$ and $\mathrm{C}$ in Figure 4). While these fronts occur in all seasons, their distribution contracts to the SW in summer and autumn (Figure 5) and a separate band of elevated frontal probability develops over the crest of the Reykjanes Ridge. The fact that the bands of higher front frequency north of the CGFZ tend to align with the MAR crest reflects the more effective barrier to ocean currents provided by the shallower crest here than further south.

The two northern ECOMAR moorings were to the south of these features in an area of infrequent fronts. The two sites have similar surface physical attributes and are likely to have a biologically similar regime (Tilstone et al., in press). Further north and west there are occasional fronts associated with the branch of the NAC (labelled C) that passes between Iceland and Greenland.

A majority of these frontal features are observed across all seasons (Figure 5), though there are some important aspects of seasonal variability that are highlighted in Figure 6, which was calculated as the standard deviation of the seasonal front frequency maps. The most prominent variability is observed in the position and strength of fronts along the coast of Greenland and across the Denmark Strait to Iceland, caused by the winter extent of sea ice. There is also significant variability in the Rockall Trough (east of B). Within the subpolar gyre, there is pronounced seasonality in the NE Irminger Basin where SST fronts largely occur in winter and spring, and over the Reykjanes ridge crest where they occur in summer and autumn. A further area of seasonal variability is inferred at $53^{\circ} \mathrm{N} 35^{\circ} \mathrm{W}$, a short distance north of where the CGFZ meets the northern section of the MAR. This appears to be due to a seasonal shift in the northern boundary of the SPF, reaching its northerly extent in summer and its southerly extent in winter. 
The northern ECOMAR stations see few fronts and little variability, whereas the southern stations experience frequent thermal fronts with greater seasonal variability at the western site than at the eastern site.

\section{Pathways across the MAR}

Understanding of the interaction between the NAC and the MAR has developed over the years (e.g. Sy, 1988, Sy et al., 1992, Rossby, 1996, Bower and von Appen, 2008). Bower and von Appen (2008) studied the pathways of the NAC using surface geostrophic currents from maps of absolute dynamic topography obtained from satellite altimetry. They discounted thermal infrared data due to persistent cloud cover, but did not benefit from the merged microwave and infrared data described here.

Therefore we consider whether the new data set can enhance or refine the altimetry-based understanding of the system.

In the region south of the CGFZ, frequent thermal fronts apparently align in zonal bands (Figure 4) and there is a temptation to think of them as representing jets or persistent currents. Using weekly altimeter data Read et al. (2010) found a broad corridor of near-stationary eddies and meanders associated with the NAC south of the CGFZ. Shoosmith et al. (2005) and Bower \& von Appen (2008) also found long-lived eddies east and west of the MAR in float and drifter data. The altimeter data used by Read et al. (2010) were incorporated into the mean absolute dynamic height of Figure 2 and were also used to obtain the mean currents of Figure 7, where current vectors are plotted over current amplitude. Figure 7 shows current cores of large amplitude crossing the MAR and their distribution closely matches the distribution of frequent thermal fronts (Figure 4). So how are the "instantaneous" (weekly) maps of eddies and meanders of Read et al. (2010) to be reconciled with the longer term images of frequent thermal fronts and mean current amplitude?

Zonal jets have been found in a number of analyses of satellite altimeter data (e.g. Maximenko et al., $2005,, 2008)$ and explanations of their formation and presence are an active area of research (e.g. Kamenkovich et al., 2009b, , 2009a). Schlax \& Chelton (2008) and Maximenko et al. (2005, , 2008) found that eddies tend to follow preferred pathways that arise from preferred generation locations either in association with permanent meanders in the current or from topographic influence. The topography of the MAR exerts a strong influence on the flow (van Aken and Becker, 1996,

Fratantoni, 2001, Bower et al., 2002, Lavender et al., 2005), therefore it is likely that there are preferential locations for eddy generation and movement. When averaged over time the eddies disappear but leave signals of their preferred locations, which appear as peaks in mean currents, as seen in Figure 7. In other words, the current cores seen in Figure 7 are weak features of the circulation that are not visible in snapshots or short time averages because they are masked by the more energetic eddy field (Nadiga and Straub, 2010).

The banded structure of the frequent surface thermal fronts (Figure 4) results from aggregating individual front observations, so is not a product of averaging. However, the bands are still more likely to indicate the preferential siting of eddies and meanders that generate the fronts, rather than zonally-coherent jets which would be more apparent on snapshots of both the thermal front and altimetry fields.

The time-series of altimeter-derived geostrophic velocities (Bower and von Appen, 2008, their figure 7 ) is reproduced in Figure 8. The data have been extended by about 4 years to include the period of the ECOMAR project. Geostrophic velocities are compared with thermal front density for the shorter period 2006-2011, calculated using a rolling 7-day period with no time filtering. Feature pathways are drawn by eye, following Bower and von Appen (2008), and it can be seen that there is generally good agreement on the number and latitude of pathways using altimetry or thermal fronts. For certain features there is excellent agreement, for instance the branching at $50.5^{\circ} \mathrm{N}$ across the western MAR section in late 2008 (white circles in Figure 8a, b) after which one branch progresses north to merge with the northern branch at about $52^{\circ} \mathrm{N}$ while the southerly branch shifts southwards towards $46^{\circ} \mathrm{N}$.

This corroborates the branching modes of the NAC pathways first identified using altimetry and enables the pathways to be tracked with increased spatial and temporal resolution. Altimetry reflects 
current and density structures that have considerable depth penetration (at least the upper half of the water column at the ECOMAR mooring sites: A. Dale, unpublished data). Microwaves reveal only the temperature of the top $1 \mathrm{~mm}$ of the water column, however the correspondence here between microwave fronts and altimetric currents gives weight to the belief that the surface thermal structure does in fact reflect deeper density structure.

Figure 8a-d follows lines of longitude (a-b $35^{\circ} \mathrm{W}$, c-d $29^{\circ} \mathrm{W}$ ). Figure $8 \mathrm{e}$ follows the line of the ridge crest and expands and extends the period of the ECOMAR project, 2006-2012. This more clearly relates the thermal front density above the MAR crest to the bathymetry of the ridge and tests for a correspondence between the NAC fronts crossing the ridge at fracture zones. The path of the ridge was derived from the GEBCO bathymetry, following the western crest of the MAR rather than the deeper trench along the middle of the ridge. As discussed earlier, there is very low density of surface thermal fronts north of the CGFZ, with only occasional appearances of fronts at or north of the Bight Fracture Zone (BFZ). The almost constant presence of surface thermal fronts at the CGFZ emphasises the importance of the deep west-to-east fracture zone. There are long periods of frontal occurrence south of the CGFZ, some of which appear to be linked to the Faraday Fracture Zone (FFZ) and the neighbouring deep MAR section 50-51 ${ }^{\circ}$ N, e.g. late 2008 - mid 2011. Frequent thermal fronts in this latitude band tend to move northwards, e.g. five occurrences from early 2007 to end 2008; or occasionally southwards as in early 2011 . These are most likely the result of mesoscale activity such as propagating eddies and meanders. In contrast, there are shorter periods of thermal fronts associated with the Maxwell Fracture Zone (MFZ), e.g. late 2007, late 2008 and late 2011; and most fronts appear to be located preferentially to the south of the fracture zone.

The mean seasonal thermal front frequency was extracted from a $3 \times 3$ pixel window centred on each position along the crest of the ridge and is shown in Figure 9. In winter, peaks indicate more frequent fronts across the Maxwell, Faraday and Bight Fracture Zones in addition to the main pathway through the CGFZ. However there is also a peak at $46^{\circ} \mathrm{N}$, related to the persistent thermal fronts south of the MFZ in Figure 8e. There is no obvious passage through the ridge at this latitude (Figure 9b) but an unnamed small-offset fracture zone, identified by Muller \& Roest (1992), might be influencing the water structure. This figure represents a novel result relating the occurrence of surface ocean fronts to deep ocean bathymetry, through the steering of current pathways that affect the entire water column.

Although thermal front frequency peaks at the CGFZ in all seasons (Figure 9) the fronts extend further north in summer and autumn, as shown by the seasonal disparity between $52.5-54.0^{\circ} \mathrm{N}$. The mechanism for this seasonal difference is unclear, but may be associated with seasonal progression of surface heating or wind stress (White and Heywood, 1995). Thermal front frequency is less consistent at other fracture zones, for example, there are no summer peaks at FFZ or BFZ. This may result from seasonal stratification or variability in the current strength and paths.

\section{Interannual variability of NAC fronts}

The next question is to consider the interannual variability of the zonal bands observed in the front frequency. Figure 10a indicates the interannual variability of the thermal fronts observed across the north Atlantic in spring during 2006-2011; the other seasons yield similar results not shown here. This was calculated as the standard deviation of the seasonal front frequency over all years. Near the MAR, there is most interannual variability south of CGFZ, forming patchy zonal bands from approximately 36 to $20^{\circ} \mathrm{W}$. This suggests that the NAC pathways are not randomly located, but switch between a number of preferred latitudes; however the limitation of six years of merged SST data prevents a more detailed exploration of longer term trends and variability. Belkin and Levitus (1996) linked significant shifts in NAC front locations to the propagation of basin-scale salinity anomalies.

Figure 10b explores the relationship between the interannual variability and the observed front frequency in spring. The underlying image is the spring front frequency map (see Figure 4), and areas with higher interannual variability (SD>15\%) have been masked out in white. The remaining areas hence have a similar spring front frequency from year to year, and the colours discriminate the recurring frontal zones (green to red, frequency $>40 \%$ ) from the recurring non-frontal zones (purple to blue, frequency $<30 \%$ ), with grey for intermediate frequencies $30-40 \%$. This map indicates the 
most stable band of the SPF along $52^{\circ} \mathrm{N}$ from 44 to $30^{\circ} \mathrm{W}$, and the two branches either side of the Rockall Bank. There are few locations along the western MAR axis that have consistently higher front frequency: near $50^{\circ} \mathrm{N}$ close to the southern ECOMAR stations; and at $43.5^{\circ} \mathrm{N}$.

This figure also reveals several recurring non-front zones (coloured blue/purple and delineated by ellipses), for instance the large area bounded to the west by the Reykjanes Ridge and to the south by the CGFZ, and several smaller rounded areas near $54^{\circ} \mathrm{N} 25^{\circ} \mathrm{W}, 53^{\circ} \mathrm{N} 26^{\circ} \mathrm{W}$, and $51^{\circ} \mathrm{N} 27^{\circ} \mathrm{W}$. It is proposed that these describe ocean current 'no go' areas, for instance the interior of persistent eddies or larger circulations. Many of these non-front zones match eddies in the streamlines derived from subsurface floats (Figure 3a in Bower et al., 2002).

\section{Fronts along the Irminger Current / Reykjanes Ridge}

The observed distribution of SST fronts along and west of the Reykjanes Ridge closely parallels the occurrence of surface salinity fronts in along-track vessel data (Despres et al., 2011). Despres et al. propose that fronts on the western flank of the Reykjanes Ridge correspond to the topographicallystabilised eastern edge of the Irminger Current, whereas the second region of fronts (' $\mathrm{C}$ ' in Figure 4), in the central Irminger Basin, arises from mesoscale straining and local intensification of the broad salinity gradients of that area. Altimeter data show no clear seasonality in mesoscale activity in the Irminger Basin, so the observed summer contraction in the distribution of SST fronts is likely due to masking of deep structure by the seasonal thermocline. The development of a band of frontal occurrence over the ridge crest in summer is thought to reflect internal tidal mixing partially eroding the seasonal thermocline and locally bringing cooler water to the surface.

The surface mixing indicated by the fronts may be responsible for the increased zooplankton and pelagic fish populations observed over the Reykjanes Ridge using acoustic sensors (Vecchione et al., 2010). The primary production over the Reykjanes Ridge, while lower than within the SPF, is significantly higher than the off-ridge regions (Tilstone et al., in press).

\section{Conclusions}

The approach to combine thermal front detection with altimetry has provided new information on the spatial and seasonal distribution of ocean fronts in the $\mathrm{N}$ Atlantic. It is apparent that where the MAR bathymetry influences surface currents within the NAC, that this is also exhibited in the patterns of surface front observations. However this influence varies considerably over spatial scales of $10 \mathrm{~s}$ of $\mathrm{kms}$, and seasonally. The observations of seasonality are novel, and will require additional research to identify the sources of this variability.

Surface thermal fronts aggregated over 28 years show preferential occurrence across the ridge and the CGFZ. North of the CGFZ there are few thermal fronts, contrasting with the region south of the fracture zone, where there are frequent surface thermal fronts that are persistent both seasonally and from year to year.

Both satellite altimetry and frequent thermal fronts show branching on approach to the MAR. Surface thermal fronts appear in bands, aligned west to east in the area south of the CGFZ, and aligned roughly SW to NE in the north. This alignment follows the direction of the NAC, across the ridge at and south of the CGFZ and following the currents of the subpolar gyre in the Rockall Trough, Iceland Basin and Irminger Basin. The latter has the most pronounced seasonal variability. The alignment of these bands of surface thermal fronts confirms altimetric and drifter observations that the shallower Reykjanes Ridge north of the CGFZ is more of a barrier to water movements than the ridge to the south.

The MAR evidently exerts strong topographic control on the presence and persistence of surface thermal fronts several thousand metres above. Further research is needed to elucidate the generalisation of this relationship, for example to estimate the size and depth of topographic features that can influence the generation of surface fronts. This controls an important source of surface mixing that impacts upon biological productivity, as is already apparent in the vicinity of seamounts (Morato et al., 2010). Further study is needed on the influence of surface fronts on the abundance of 
phytoplankton, zooplankton and higher trophic levels (Scales et al., in prep.). It is already clear that lateral stirring by eddies results in higher productivity throughout the SPF region (Tilstone et al., in press).

There appears to be great potential for the complementary use of EO-derived oceanic fronts to reveal details of surface currents that cannot be resolved using satellite altimetry or in situ measurements. Thermal fronts derived from merged microwave and infrared data will be particularly useful for visualising surface processes in other cloud-affected regions, where it is not possible to gain prolonged observations using visible or infrared EO data.

\section{Acknowledgements}

The ECOMAR consortium is funded by UK Natural Environment Research Council grant NE/C512961/1, and forms a component of the wider MAR-ECO project. AVHRR satellite data were received and processed by the NERC Earth Observation Data Acquisition and Analysis Service (NEODAAS) at Dundee University and Plymouth Marine Laboratory (www.neodaas.ac.uk). Merged microwave and infrared SST data were provided by Remote Sensing Systems (www.ssmi.com). The altimeter products were produced by SSALTO/DUACS and distributed by AVISO, with support from CNES (www.aviso.oceanobs.com/duacs/). Weidong Xu (PML) assisted with Hovmöller plots. The authors thank two anonymous reviewers for helpful comments.

\section{References}

Belkin, I.M., Cornillon, P.C. \& Sherman, K. (2009) Fronts in Large Marine Ecosystems. Progress In Oceanography, 81(1-4), 223-236.

Belkin, I.M. \& Levitus, S. (1996) Temporal variability of the subarctic front near the Charlie-Gibbs fracture zone. Journal of Geophysical Research-Oceans, 101(C12), 28317-28324.

Bower, A.S., Le Cann, B., Rossby, T., Zenk, W., Gould, J., Speer, K., Richardson, P.L., Prater, M.D. \& Zhang, H.M. (2002) Directly measured mid-depth circulation in the northeastern North Atlantic Ocean. Nature, 419(6907), 603-607.

Bower, A.S. \& von Appen, W.-J. (2008) Interannual variability in the pathways of the North Atlantic current over the Mid-Atlantic Ridge and the impact of topography. Journal of Physical Oceanography, 38(1), 104-120.

Despres, A., Reverdin, G. \& d'Ovidio, F. (2011) Mechanisms and spatial variability of meso scale frontogenesis in the northwestern subpolar gyre. Ocean Modelling, 39(1-2), 97-113.

Flatau, M.K., Talley, L. \& Niiler, P.P. (2003) The North Atlantic Oscillation, surface current velocities, and SST changes in the subpolar North Atlantic. Journal of Climate, 16(14), 23552369.

Fratantoni, D.M. (2001) North Atlantic surface circulation during the 1990's observed with satellitetracked drifters. Journal of Geophysical Research-Oceans, 106(C10), 22067-22093.

Gentemann, C.L., Minnett, P.J., Sienkiewicz, J., DeMaria, M., Cummings, J., Jin, Y., Doyle, J.D., Gramer, L., Barron, C.N., Casey, K.S. \& Donlon, C.J. (2009) MISST: the Multi-Sensor Improved Sea Surface Temperature Project. Oceanography, 22(2), 76-87.

Jayne, S.R. (2006) Circulation of the North Atlantic Ocean from altimetry and the Gravity Recovery and Climate Experiment geoid. Journal of Geophysical Research-Oceans, 111(C3).

Kamenkovich, I., Berloff, P. \& Pedlosky, J. (2009a) Anisotropic material transport by eddies and eddy-driven currents in a model of the North Atlantic. Journal of Physical Oceanography, 39(12), 3162-3175.

Kamenkovich, I., Berloff, P. \& Pedlosky, J. (2009b) Role of eddy forcing in the dynamics of multiple zonal jets in a model of the North Atlantic. Journal of Physical Oceanography, 39(6), 13611379.

Krauss, W. (1986) The North-Atlantic Current. Journal of Geophysical Research-Oceans, 91(C4), 5061-5074. 
Lavender, K.L., Owens, W.B. \& Davis, R.E. (2005) The mid-depth circulation of the subpolar North Atlantic Ocean as measured by subsurface floats. Deep-Sea Research Part I-Oceanographic Research Papers, 52(5), 767-785.

Maximenko, N.A., Bang, B. \& Sasaki, H. (2005) Observational evidence of alternating zonal jets in the world ocean. Geophysical Research Letters, 32(12).

Maximenko, N.A., Melnichenko, O.V., Niiler, P.P. \& Sasaki, H. (2008) Stationary mesoscale jet-like features in the ocean. Geophysical Research Letters, 35(8).

Miller, P., Groom, S., McManus, A., Selley, J. \& Mironnet, N. (1997) Panorama: a semi-automated AVHRR and CZCS system for observation of coastal and ocean processes. RSS97: Observations and Interactions, Proceedings of the Remote Sensing Society. Reading, pp. 539544.

Miller, P.I. (2009) Composite front maps for improved visibility of dynamic sea-surface features on cloudy SeaWiFS and AVHRR data. Journal of Marine Systems, 78(3), 327-336, doi:10.1016/j.jmarsys.2008.11.019.

Miller, P.I. \& Christodoulou, S. (2014) Frequent locations of oceanic fronts as an indicator of pelagic diversity: application to marine protected areas and renewables. Marine Policy, 45, 318-329.

Morato, T., Hoyle, S.D., Allain, V. \& Nicol, S.J. (2010) Seamounts are hotspots of pelagic biodiversity in the open ocean. Proceedings of the National Academy of Sciences of the United States of America, 107(21), 9707-9711.

Muller, R.D. \& Roest, W.R. (1992) Fracture-Zones in the North-Atlantic from Combined Geosat and Seasat Data. Journal of Geophysical Research-Solid Earth, 97(B3), 3337-3350.

Nadiga, B.T. \& Straub, D.N. (2010) Alternating zonal jets and energy fluxes in barotropic winddriven gyres. Ocean Modelling, 33(3-4), 257-269.

Perez-Brunius, P., Rossby, T. \& Watts, D.R. (2004) Absolute transports of mass and temperature for the North Atlantic Current-subpolar front system. Journal of Physical Oceanography, 34(8), 1870-1883.

Pollard, R.T., Griffiths, M.J., Cunningham, S.A., Read, J.F., Perez, F.F. \& Rios, A.F. (1996) Vivaldi 1991-A study of the formation, circulation and ventilation of Eastern North Atlantic Central Water. Progress in Oceanography, 37(2), 167-192.

Priede, I.G., Bergstad, O.A., Miller, P.I., Vecchione, M., Gebruk, A., Falkenhaug, T., Billett, D.S.M., Craig, J., Dale, A.C., Shields, M.A., Tilstone, G.H., Sutton, T.T., Gooday, A.J., Inall, M.E., Jones, D.O.B., Martinez-Vicente, V., Menezes, G.M., Niedzielski, T., Sigurðsson, o., Rothe, N., Rogacheva, A., Alt, C.H.S., Abell, R., Brierley, A.S., Cousins, N.J., Crockard, D., Hoelzel, A.R., Høines, Å., Letessier, T.B., Read, J.F., Shimmield, T., Cox, M.J., Galbraith, J.K., Gordon, J.D.M., Horton, T., Neat, F. \& Lorance, P. (2013a) Does presence of a Mid Ocean Ridge enhance biomass and biodiversity? PLOS One, 8(5), e61550. doi: 10.1371/journal.pone.0061550

Priede, I.G., Billett, D.S.M., Brierley, A.S., Hoelzel, A.R., Inall, M. \& Miller, P.I. (2013b) The ECOMAR (Ecosystem of the Mid-Atlantic Ridge at the Sub-Polar Front and Charlie Gibbs Fracture Zone) project and description of the benthic sampling programme 2007-2010. Marine Biology Research, 9(5-6), 624-628. doi: 10.1080/17451000.2012.749998

Read, J.F., Pollard, R.T., Miller, P.I. \& Dale, A.C. (2010) Circulation and variability of the North Atlantic Current in the vicinity of the Mid-Atlantic Ridge. Deep Sea Research Part I: Oceanographic Research Papers, 57(3), 307-318.

Rio, M.H., Guinehut, S. \& Larnicol, G. (2011) New CNES-CLS09 global mean dynamic topography computed from the combination of GRACE data, altimetry, and in situ measurements. Journal of Geophysical Research-Oceans, 116.

Rossby, T. (1996) The North Atlantic Current and surrounding waters: At the crossroads. Reviews of Geophysics, 34(4), 463-481.

Scales, K.L., Miller, P.I., Hawkes, L.A., Ingram, S.N., Votier, S.C. \& Sims, D.W. (in revision) On the front line: frontal zones as priority conservation areas for pelagic predators? Journal of Applied Ecology.

Schlax, M.G. \& Chelton, D.B. (2008) The influence of mesoscale eddies on the detection of quasizonal jets in the ocean. Geophysical Research Letters, 35(24). 
Shoosmith, D., Richardson, P.L., Bower, A.S. \& Rossby, H.T. (2005) Discrete eddies in the northern North Atlantic as observed by looping RAFOS floats. Deep-Sea Research Part II-Topical Studies in Oceanography, 52(3-4), 627-650.

Sy, A. (1988) Investigation of large-scale circulation patterns in the central North-Atlantic - the North-Atlantic Current, the Azores Current, and the Mediterranean water plume in the area of the Mid-Atlantic Ridge. Deep-Sea Research Part I-Oceanographic Research Papers, 35(3), 383-413.

Sy, A., Schauer, U. \& Meincke, J. (1992) The North-Atlantic Current and its associated hydrographic structure above and eastwards of the Mid-Atlantic Ridge. Deep-Sea Research Part IOceanographic Research Papers, 39(5A), 825-853.

Tilstone, G.H., Miller, P.I., Brewin, R.J.W. \& Priede, I.G. (in press) Enhancement of primary production in the North Atlantic outside of the spring bloom. Remote Sensing of Environment.

van Aken, H.M. \& Becker, G. (1996) Hydrography and through-flow in the north-eastern North Atlantic Ocean: the NANSEN project. Progress in Oceanography, 38(4), 297-346.

Vecchione, M., Bergstad, O., Byrkjedal, I., Falkenhaug, T., Gebruk, A., Godø, O., Gilsason, A., Heino, M., Høines, ̊̊., Menezes, G., Piatkowsk, i.U., Priede, I., Skov, H., Søiland, H., Sutton, T. \& Lande Wenneck, T. (2010) Biodiversity Patterns and Processes on the Mid Atlantic Ridge. In McIntyre, A.D. (Ed.) Life in the World's Oceans: Diversity, Distribution, and Abundance. Oxford, Wiley-Blackwell.

White, M.A. \& Heywood, K.J. (1995) Seasonal and interannual changes in the North Atlantic subpolar gyre from Geosat and TOPEX/POSEIDON altimetry. Journal of Geophysical Research-Oceans, 100(C12), 24931-24941. 


\section{Figure legends}

Figure 1. Bathymetry of MAR region, derived from GEBCO. The white box indicates the subregion analysed for AVHRR thermal fronts.

Figure 2. Sea-surface topography of MAR region from satellite altimetry, derived from maps of absolute dynamic topography (MADT) from AVISO averaged over 1992-2012. Units in $\mathrm{cm}$. Letters refer to frontal features in Fig. 4: $B=$ Rockall Bank, $M=$ Meander, $R=$ Reykjanes Ridge, $\mathrm{N}=$ Irminger Current, $\mathrm{C}=\mathrm{Central}$ Irminger Basin, $\mathrm{H}=$ Seabed trough.

Figure 3. Seasonal AVHRR thermal front frequency maps for (a) winter, (b) spring, (c) summer, (d) autumn. The colour indicates the percentage of time a strong front was observed at each location. White squares indicate ECOMAR superstations spanning two sections of the MAR north and south of the CGFZ.

Figure 4. Seasonal oceanic front frequency map indicating the percentage of time a strong front was observed at each location during spring (Mar.-May), derived from merged microwave and infrared SST data, 2006-2011. ECOMAR mooring stations are marked by white squares, blue arrow is inferred path of NAC, and letters are explained in text: $\mathrm{B}=$ Rockall Bank, M=Meander, $\mathrm{R}=$ Reykjanes Ridge, $\mathrm{N}=$ Irminger Current, $\mathrm{C}=$ Central Irminger Basin, $\mathrm{H}=$ Seabed trough .

Figure 5. Seasonal oceanic front frequency map indicating the percentage of time a strong front was observed at each location, derived from merged microwave and infrared SST data: (a) winter (Dec.-Feb.); (b) summer (Jun.-Aug.); (c) autumn (Sep.-Nov.). For spring see Figure 4.

Figure 6. Seasonal variability in front frequency, calculated as the standard deviation of the seasonal front frequency maps.

Figure 7. Geostrophic currents across MAR region, derived from MADT from AVISO satellite altimetry, averaged over 1992-2012. Current vectors are plotted as black arrows over the coloured current amplitude in $\mathrm{cm} \mathrm{s}^{-1}$.

Figure 8. Latitude vs. time plots of branches of NAC: (a) zonal velocity at $35^{\circ} \mathrm{W}$ from MADT; (b) thermal front density at $35^{\circ} \mathrm{W}$; (c) zonal velocity at $29^{\circ} \mathrm{W}$; (d) thermal front density at $29^{\circ} \mathrm{W}$. Branches are highlighted subjectively by transparent black lines, and branching patterns indicated at the top. A key branching point is ringed in (a) and (b). (e) Thermal front density along curved MAR crest from 45 to $60^{\circ} \mathrm{N}$. The grey region indicates the transition of the MAR crest from the southeast $\left(30^{\circ} \mathrm{W}\right)$ to northwest $\left(35^{\circ} \mathrm{W}\right)$ branch of the MAR through the CGFZ. Other fracture zones are labelled: Faraday (FFZ), Maxwell (MFZ) and Bight (BFZ).

Figure 9. Analysis of thermal front distribution along MAR crest: (a) seasonal front frequency showing peaks at crossing points of NAC; winter is highlighted with a darker line; (b) depth of MAR crests along axis, labelled with fracture zones: Charlie-Gibbs (CGFZ), Faraday (FFZ), Maxwell (MFZ) and Bight (BFZ). The grey region indicates the transition of the MAR crest from the southeast $\left(30^{\circ} \mathrm{W}\right)$ to northwest $\left(35^{\circ} \mathrm{W}\right)$ branch of the MAR through the CGFZ.

Figure 10. Interannual variability in thermal fronts: (a) interannual standard deviation in spring front frequency (percentage of time); (b) spring front frequency map, highlighting regions of lower interannual variability (SD>15\% masked in white). The colours indicate the percentage of time, with the addition of grey indicating 30-40\% to separate low and high frequency fronts. Dashed ellipses delineate recurring non-front zones. 


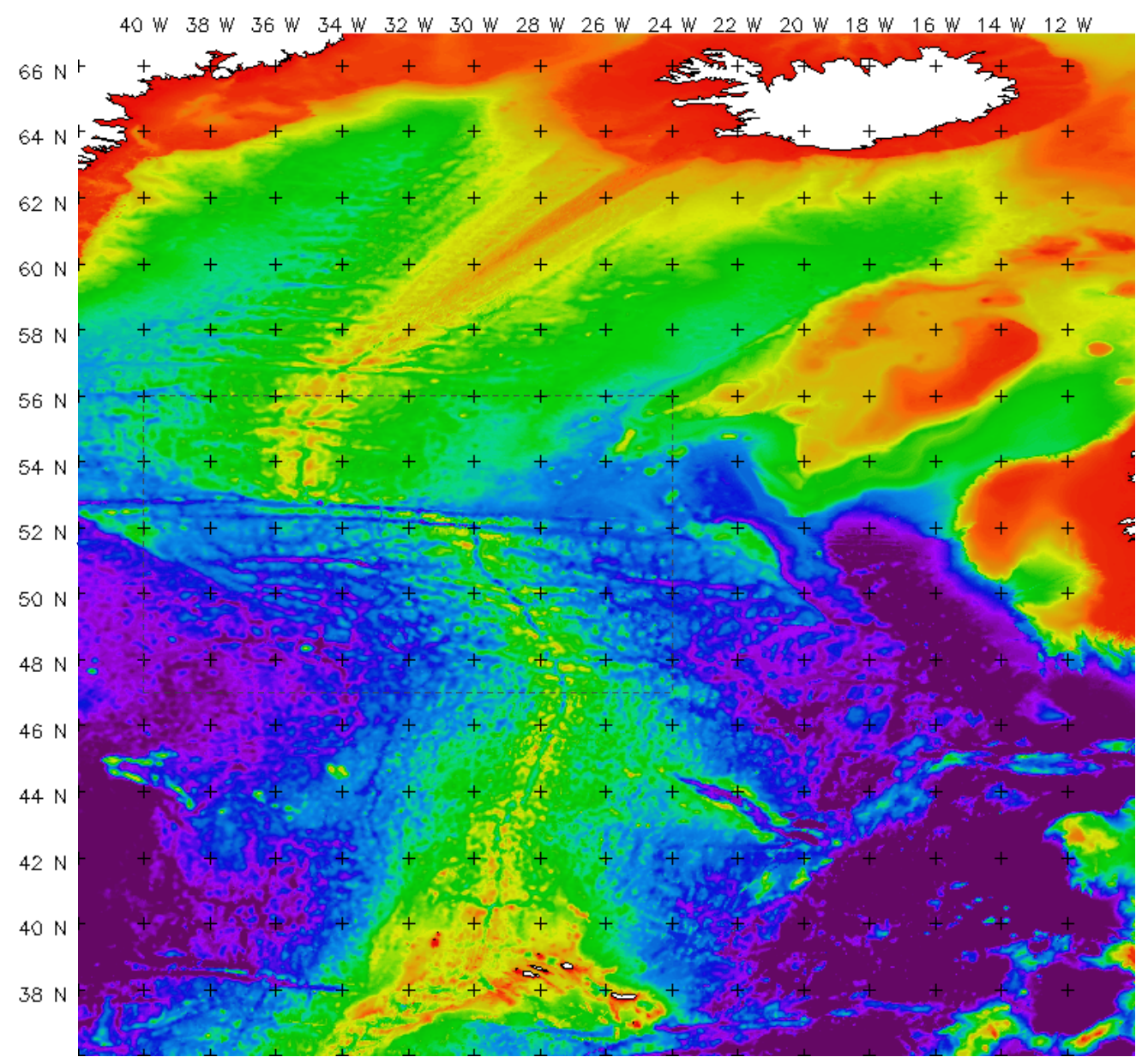

Figure 1. Bathymetry of MAR region, derived from GEBCO. The dashed box indicates the subregion analysed for AVHRR thermal fronts

\section{Thermal front variability along the North Atlantic Current observed using microwave and infrared satellite data}

Peter Miller, Jane Read and Andy Dale

Paper for ECOMAR special issue in DSR-II

Figures v5, 26 Feb. 2013 


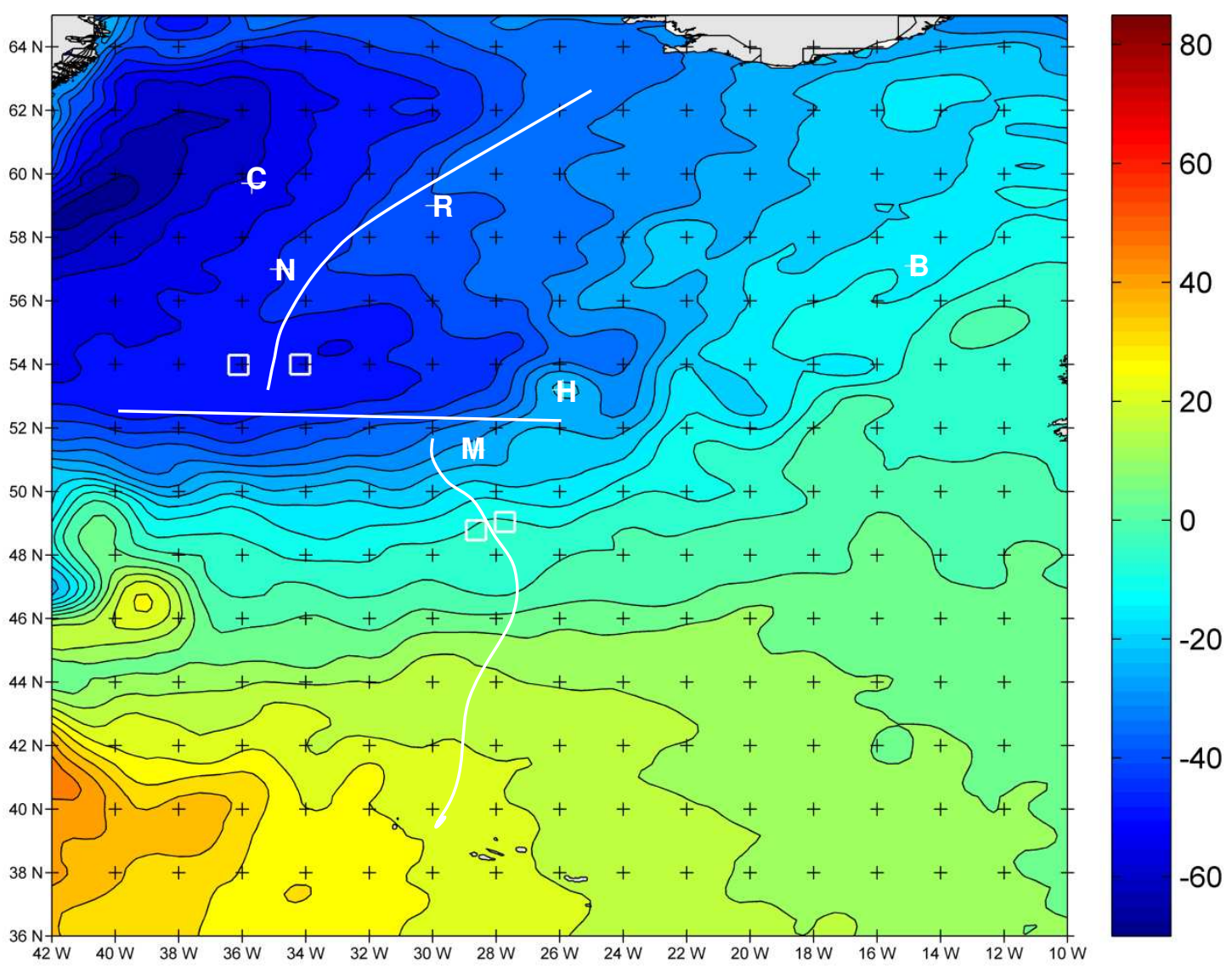

Figure 2. Sea-surface topography of MAR region from satellite altimetry, derived from maps of absolute dynamic topography (MADT) from AVISO averaged over 1992-2012. Units in $\mathrm{cm}$. Letters refer to frontal features in Fig. 4: $B=$ Rockall Bank, $M=$ Meander, $R=$ Reykjanes Ridge, $\mathrm{N}=$ Irminger Current, $\mathrm{C}=$ =Central Irminger Basin, $\mathrm{H}=$ Seabed trough. 

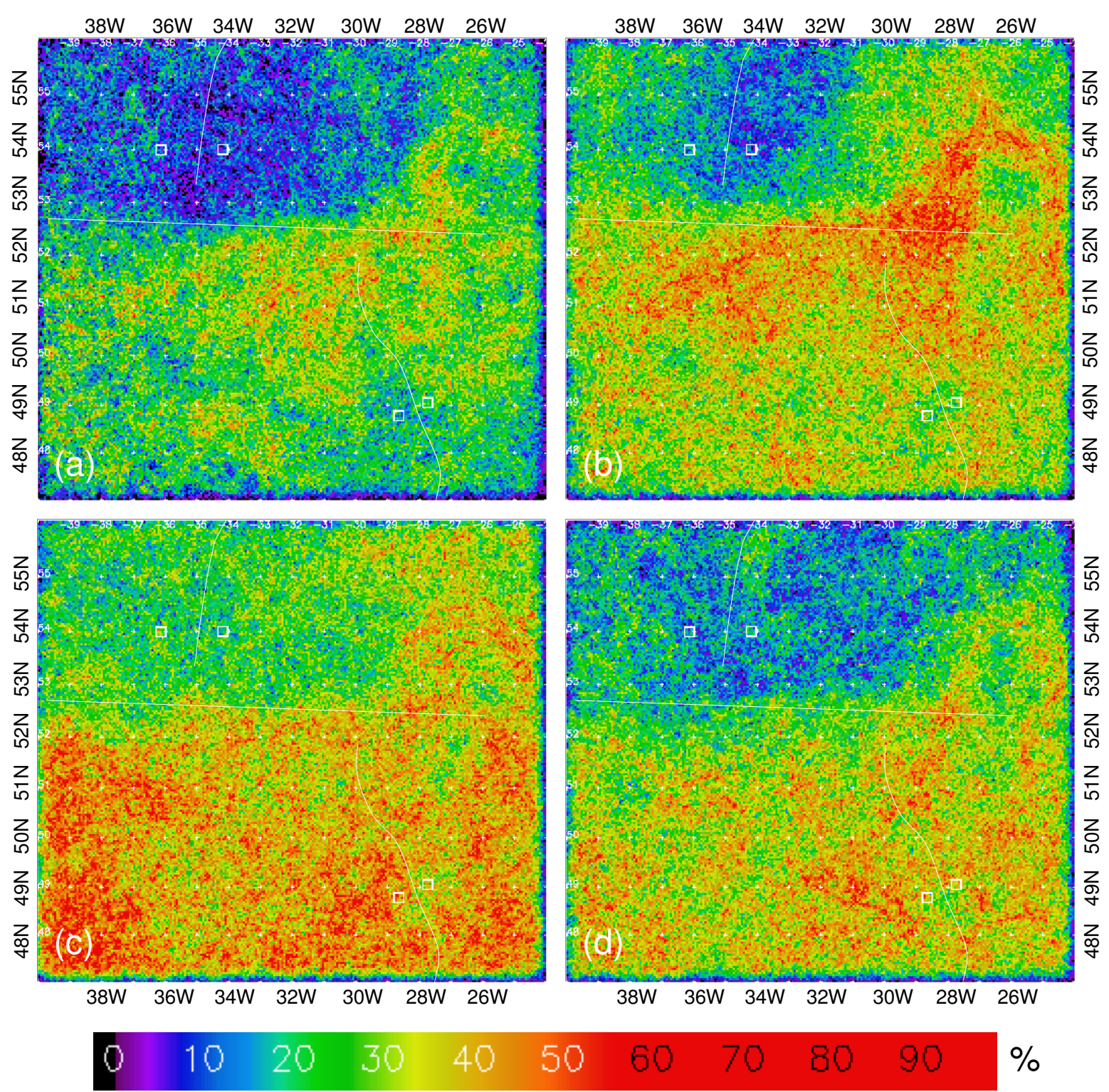

Figure 3. Seasonal AVHRR thermal front frequency maps for (a) winter, (b) spring, (c) summer, (d) autumn. The colour indicates the percentage of time a strong front was observed at each location. White squares indicate ECOMAR superstations spanning two sections of the MAR north and south of the CGFZ. 

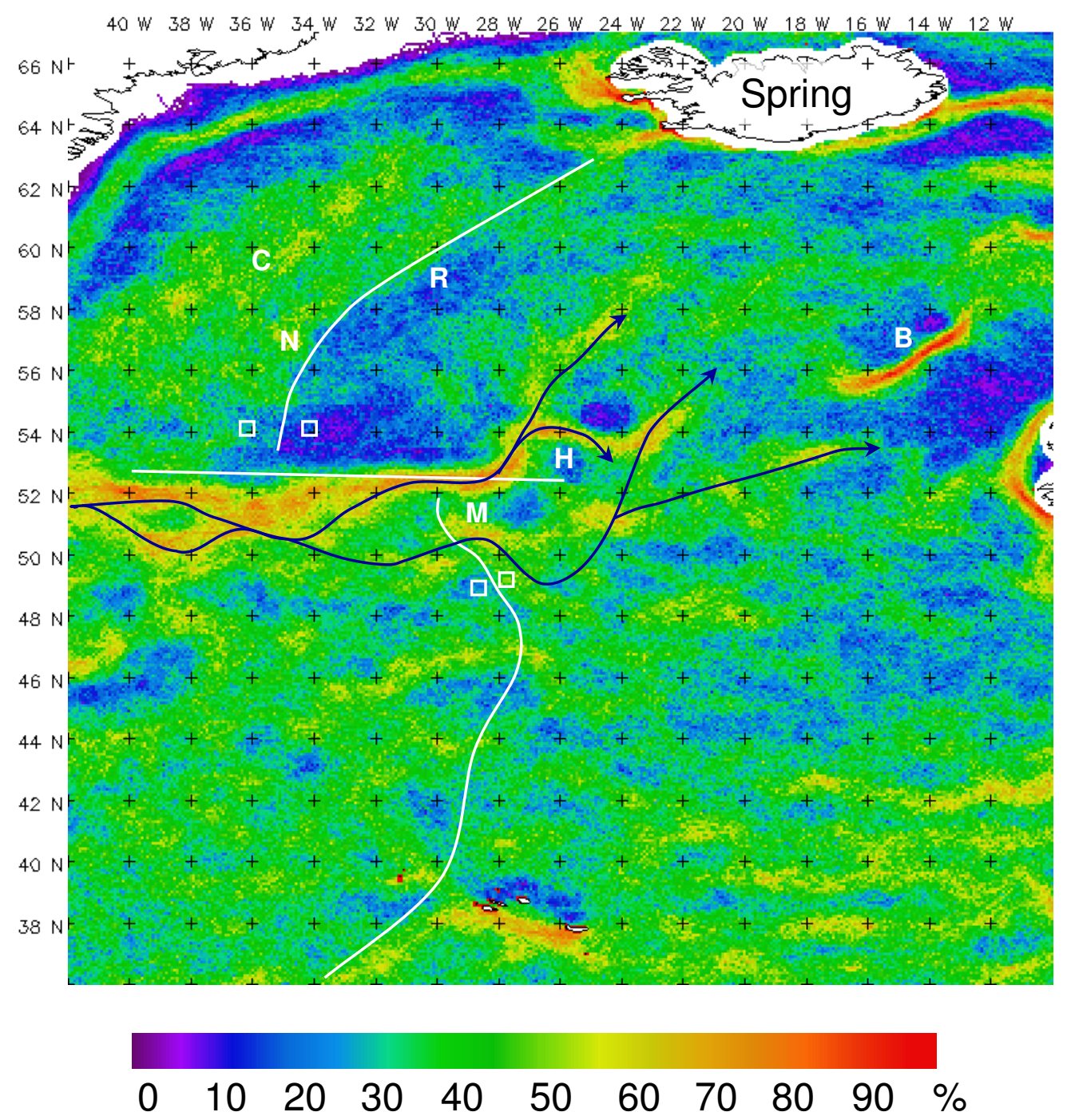

Figure 4. Seasonal oceanic front frequency map indicating the percentage of time a strong front was observed at each location during spring (Mar.-May), derived from merged microwave and infrared SST data, 2006-2011. ECOMAR mooring stations are marked by white squares, blue arrow is inferred path of NAC, and letters are explained in text: $\mathrm{B}=$ Rockall Bank, $\mathrm{M}=$ Meander, $\mathrm{R}=$ Reykjanes Ridge, $\mathrm{N}=$ Irminger Current, $\mathrm{C}=$ Central Irminger Basin, $\mathrm{H}=$ Seabed trough. 
(a)

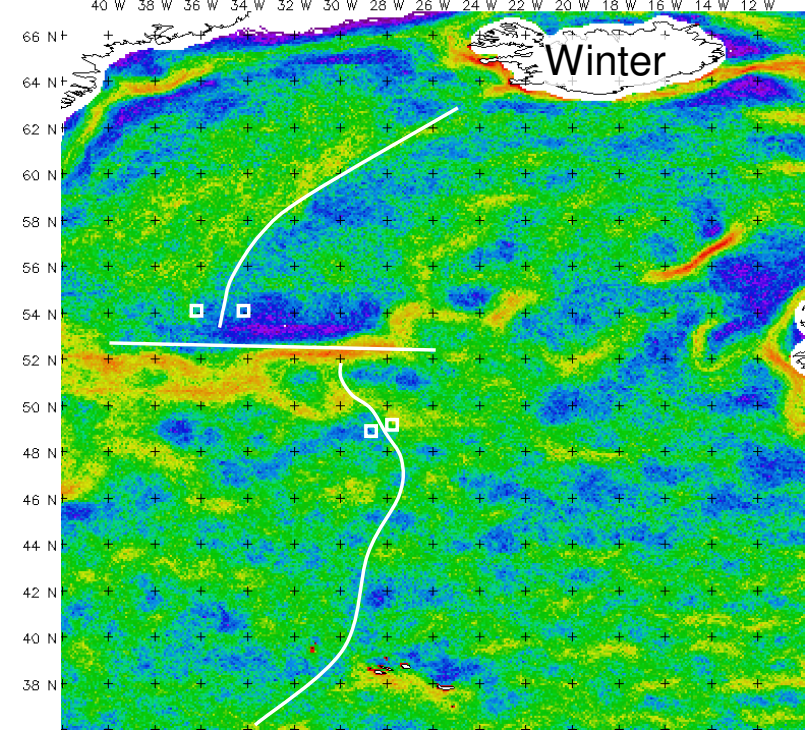

(b)

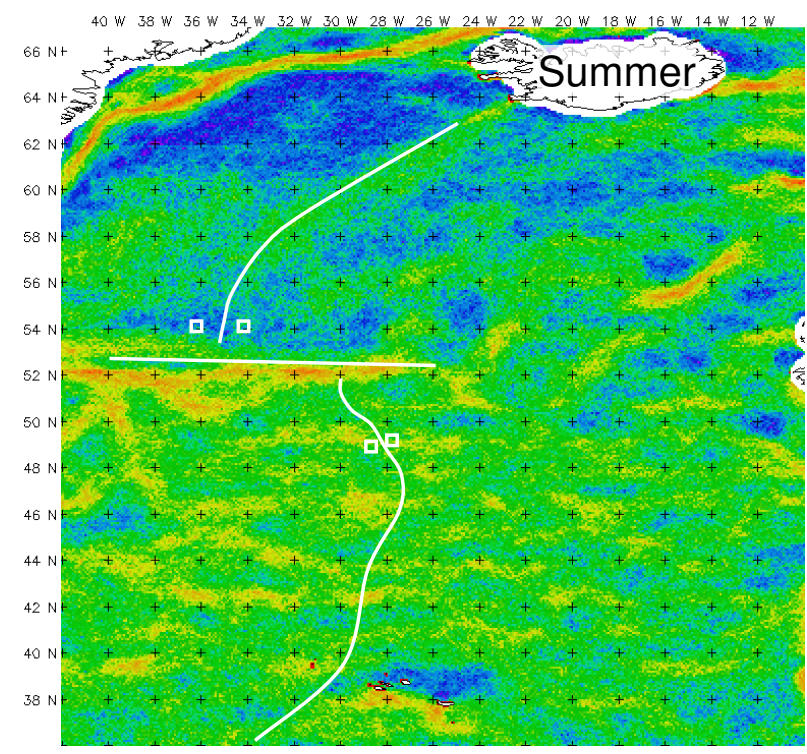

(c)

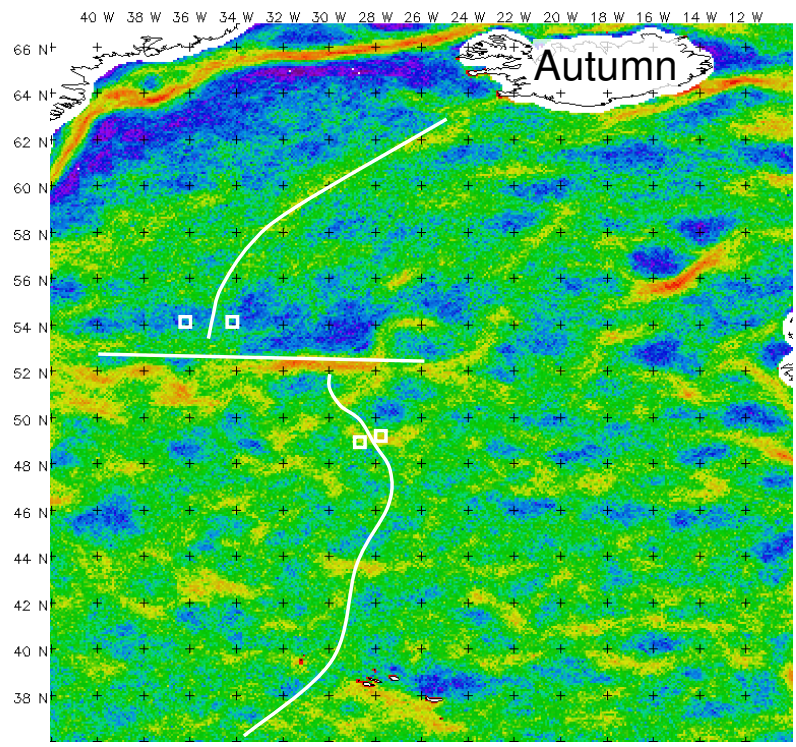

\section{$\begin{array}{lllllllllll}0 & 10 & 20 & 30 & 40 & 50 & 60 & 70 & 80 & 90 & \%\end{array}$}

Figure 5. Seasonal oceanic front frequency map indicating the percentage of time a strong front was observed at each location, derived from merged microwave and infrared SST data:

(a) winter (Dec.-Feb.); (b) summer (Jun.-Aug.); (c) autumn (Sep.-Nov.). 

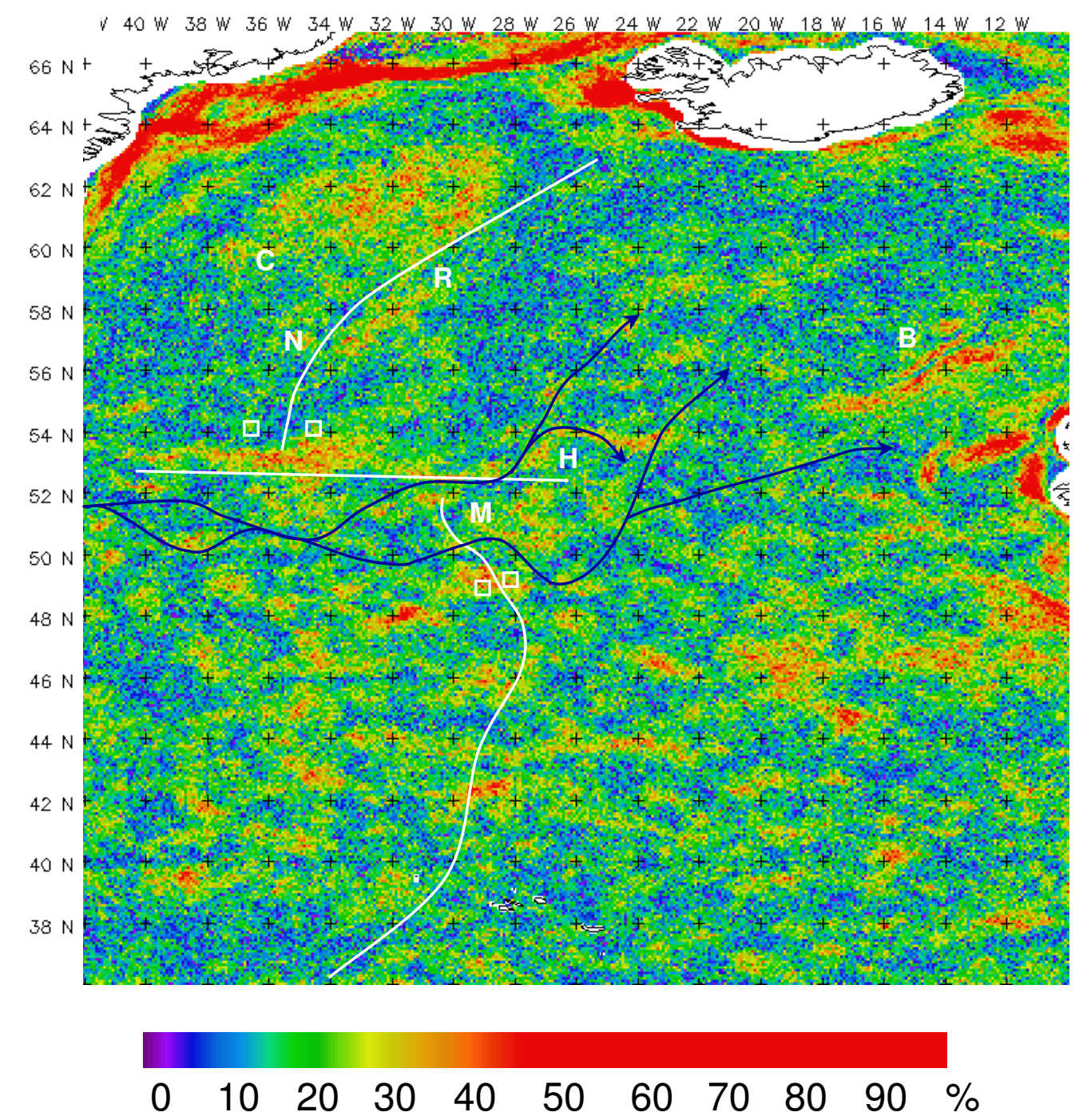

Figure 6. Seasonal variability in front frequency, calculated as the standard deviation of the seasonal front frequency maps. 


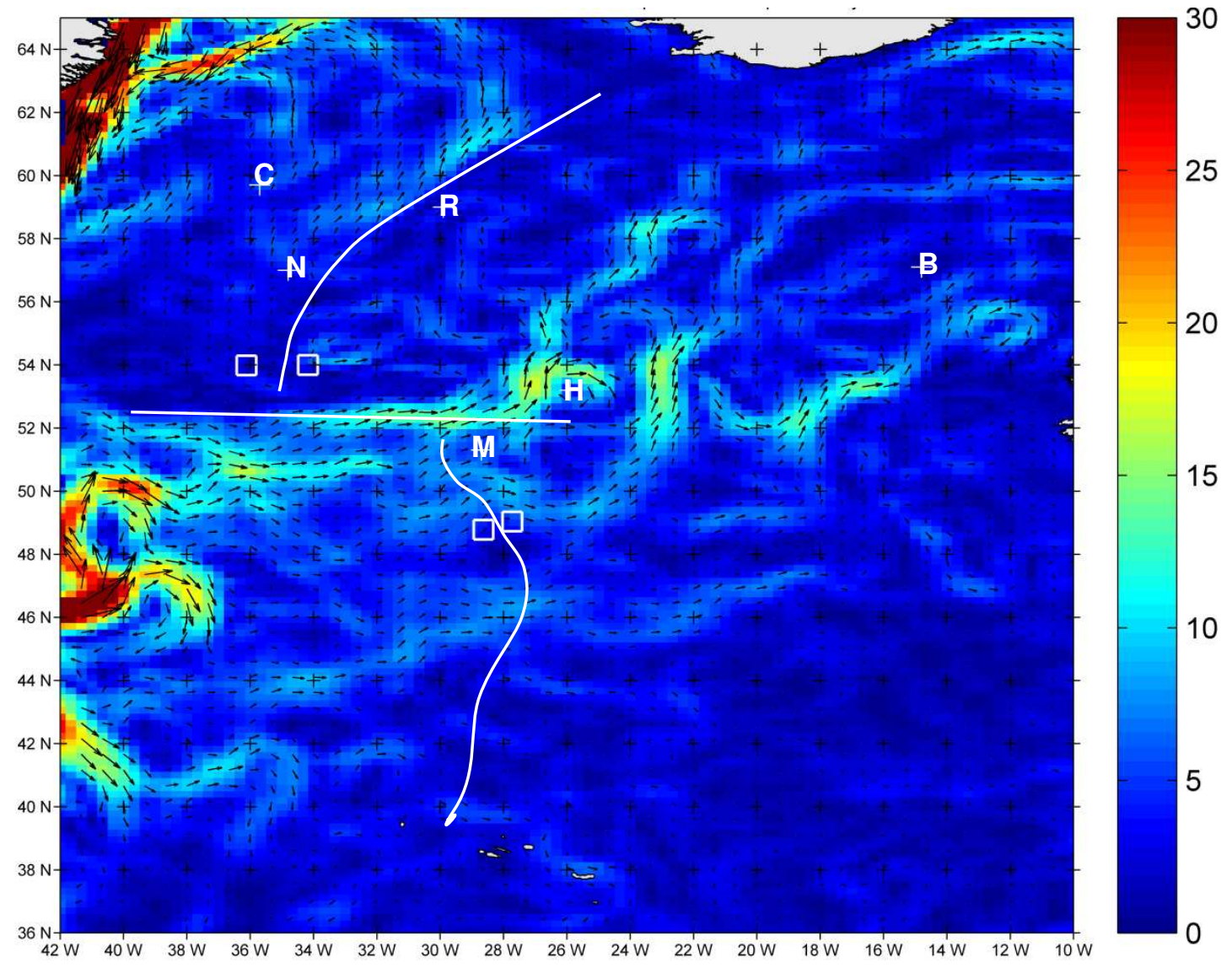

Figure 7. Geostrophic currents across MAR region, derived from MADT from AVISO satellite altimetry, averaged over 1992-2012. Current vectors are plotted as black arrows over the coloured current amplitude in $\mathrm{cm} \mathrm{s}^{-1}$. 

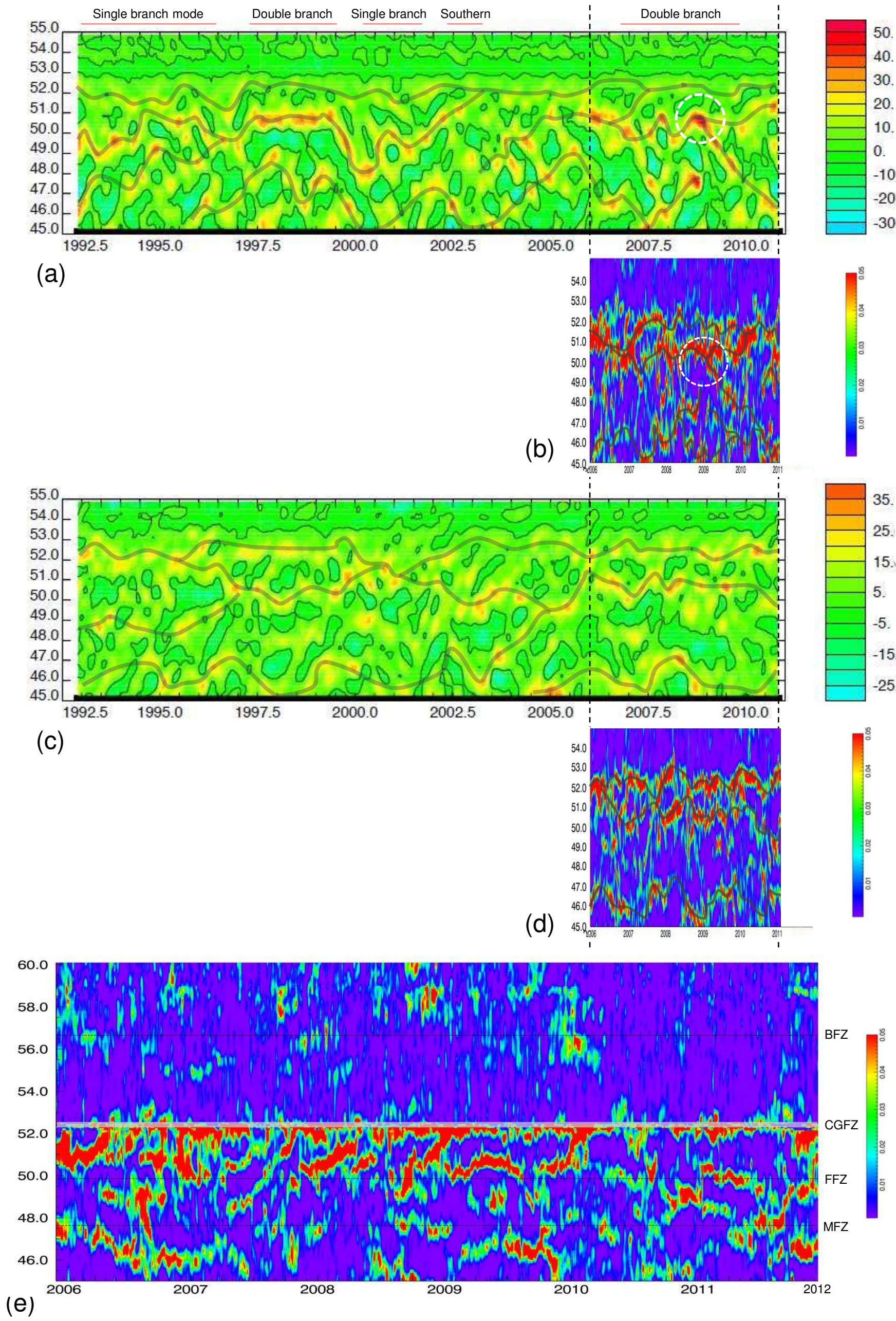

Figure 8. Latitude vs. time plots of branches of NAC [see complete figure legend after text] 

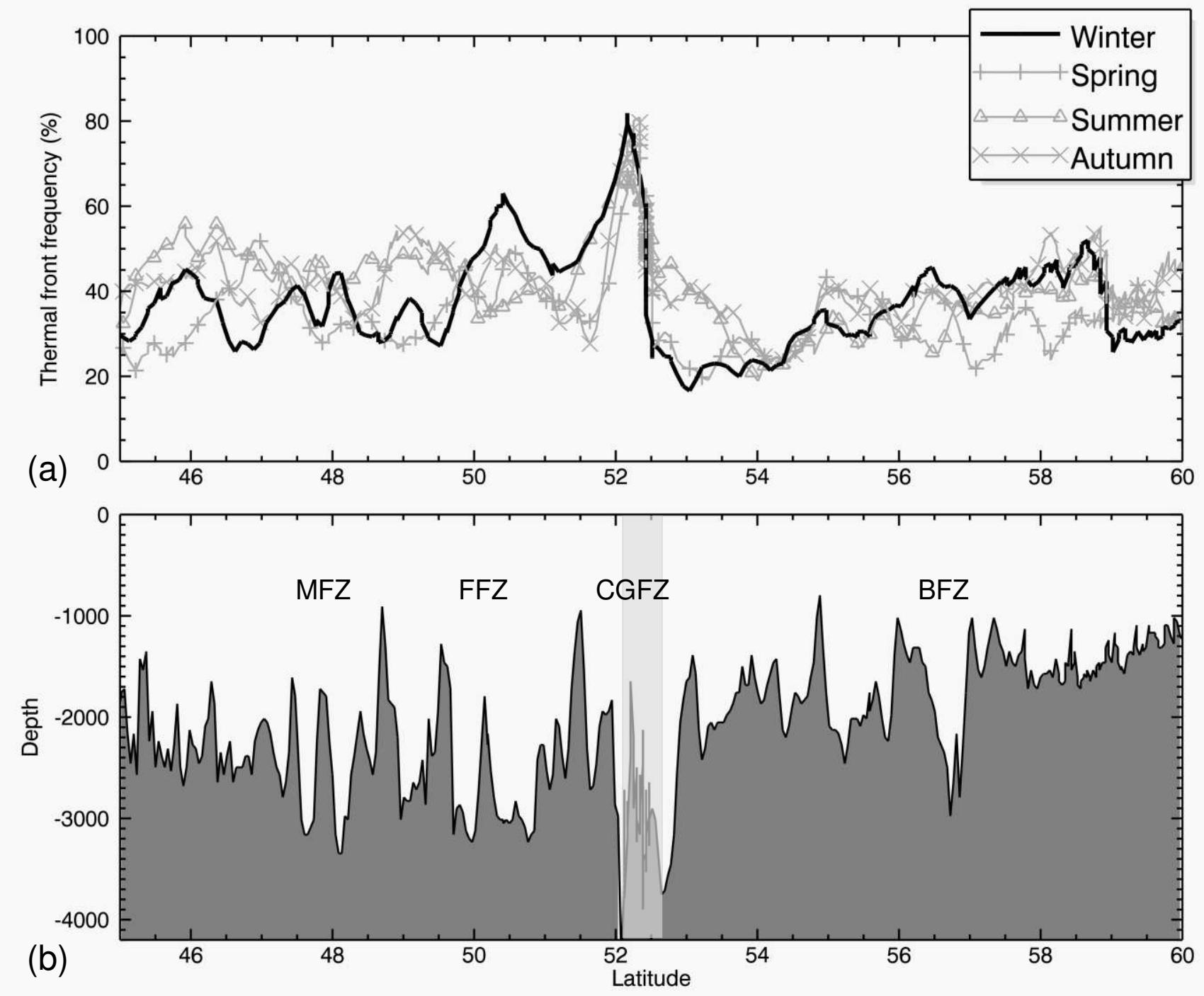

Figure 9. Analysis of thermal front distribution along MAR crest: (a) seasonal front frequency showing peaks at crossing points of NAC; (b) depth of MAR crests along axis, labelled with fracture zones: Charlie-Gibbs (CGFZ), Faraday (FFZ), Maxwell (MFZ) and Bight (BFZ). The grey region indicates the transition of the MAR crest from the southeast $\left(30^{\mathrm{W}}\right)$ to northwest $\left(35^{\mathrm{W}}\right)$ branch of the MAR through the CGFZ. 


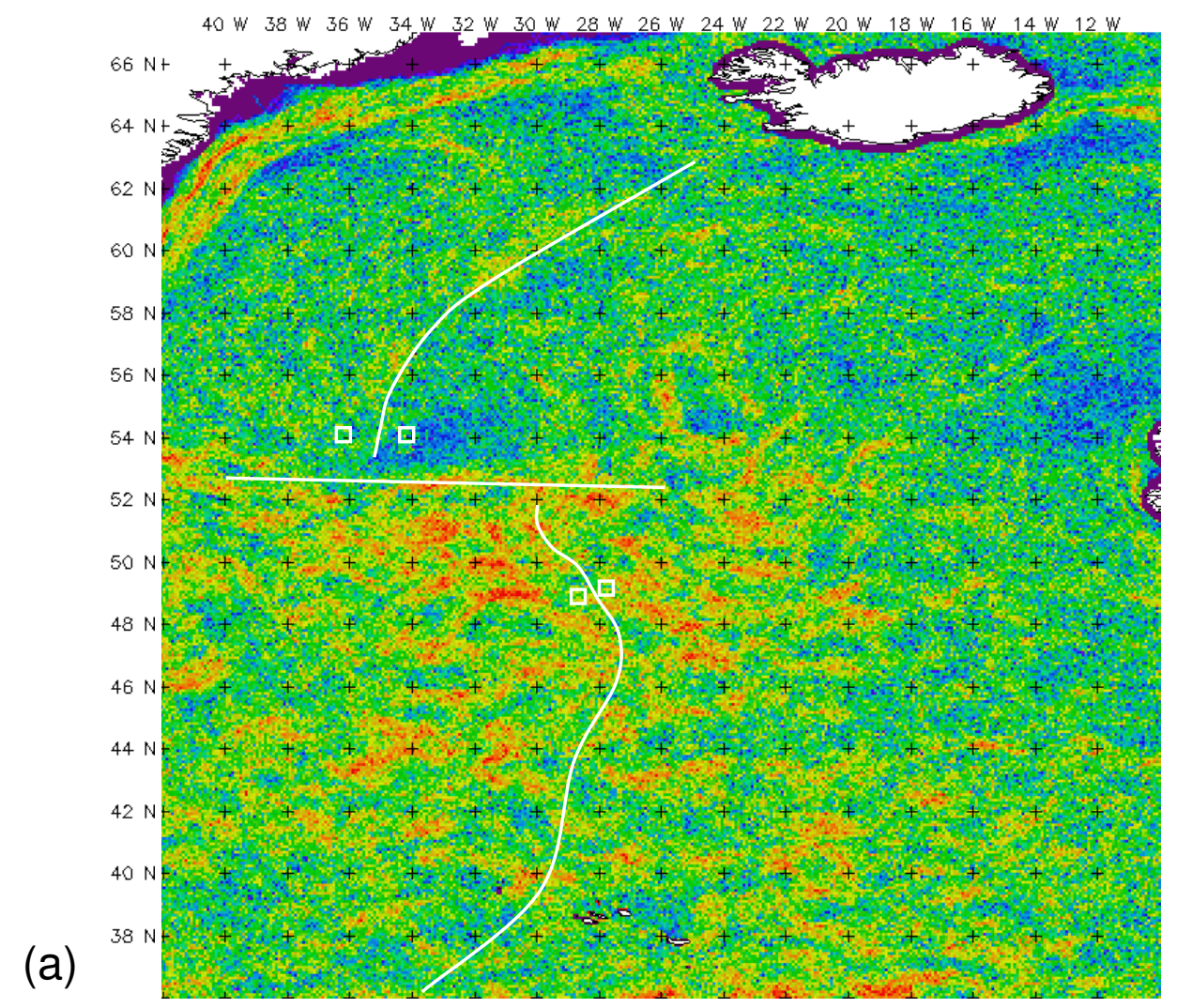

(a)

$40 \mathrm{w} 38 \mathrm{w} 36 \mathrm{w} 34 \mathrm{w} 32 \mathrm{w} 30 \mathrm{w} 28 \mathrm{w} 26 \mathrm{w}, 24 \mathrm{w} 22 \mathrm{w} 20 \mathrm{w}-18 \mathrm{w} 16 \mathrm{w}-14 \mathrm{w}-12 \mathrm{w}$
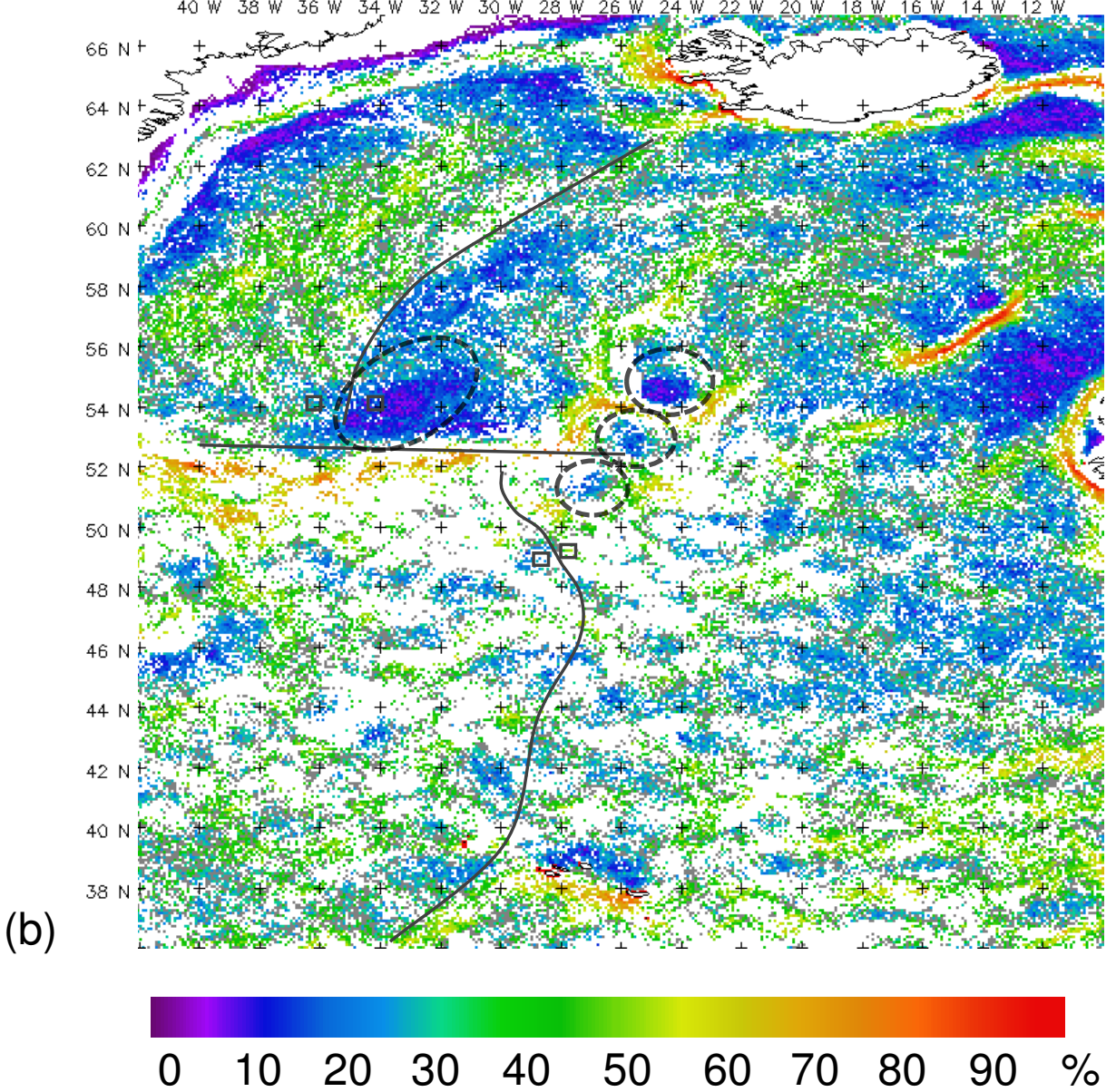

Figure 10. Interannual variability in thermal fronts: (a) interannual standard deviation in spring front frequency (percentage of time); (b) spring front frequency map, highlighting regions of lower interannual variability (SD>15\% masked in white). The colours indicate the percentage of time, with the addition of grey indicating $30-40 \%$ to separate low and high frequency fronts. Dashed ellipses delineate recurring non-front zones. 